\title{
ANALISIS KAMPANYE HARI DISABILITAS INTERNASIONAL (HDI) TAHUN 2017 KABUPATEN KLATEN
}

\author{
Angga Kusuma Dawami, Yayah Rukiah, Mohamad Sjafei Andrijanto \\ Program Studi Desain Komunikasi Visual \\ Fakultas Bahasa dan Seni, Universitas Indraprasta PGRI \\ akdawami@gmail.com;ya2hrukiah@gmail.com;ad3_sj410@yahoo.com
}

\begin{abstract}
Abstrak
Ajang peringatan Hari Disabilitas Internasional (HDI) adalah ajang untuk organisasi difabel menunjukkan dirinya merupakan bagian dari masyarakat yang utuh. Semangat untuk menjadi setara merupakan semangat yang terus digaungkan dimanapun HDI dilakukan. Difabel Klaten merupakan salah satu merek persatuan difabel, yang berbentuk organisasi, namun menjadi merek perjuangan untuk organisasi-organisasi disabilitas di Kabupaten Klaten pada HDI Klaten 2017. Materi-materi kampanye yang diproduksi oleh Difabel Klaten menjadi corak tersendiri yang mewarnai HDI tahun 2017. Produksi visual pada Kampanye Sosial oleh Difabel Klaten memberikan gambaran yang menarik dalam mencerminkan dirinya sebagai salah satu merek dalam perjuangan advokasi dari yang pernah ada. Difabel Klaten memproduksi kampanye secara visual secara terstruktur, dari Logo, Maskot, E-Banner, dll. Tulisan ini membahas tentang analisis kampanye yang dilakukan oleh Difabel Klaten pada Hari Disabilitas Internasional (HDI) tahun 2017 di Kabupaten Klaten. Dengan menggunakan deskriptif analitik, materi-materi kampanye Difabel Klaten dibahas secara komprehensif. Hasil penelitian ini adalah (1) terdapat konsistensi atas ide-ide komunikasi visual yang diproduksi oleh Difabel Klaten; (2) adanya kesinambungan antar ide kreatif dengan semangat perjuangan Difabel yang dilihat dari logo, maskot, dan produksi visual lainnya.
\end{abstract}

Kata Kunci: Hari Disabilitas Internasional, Kampanye, Difabel Klaten

\begin{abstract}
International Day of Persons with Disabilities (HDI) is a event for disabilities people that can be show themselves as a part of society. It have the spirit to be equal to sounding whereever HDI's anniversary. Difabel Klaten is one of brand of disabilities allience, which is in organization's form, but becomes a brand of grassroot's disabilities organizations in Klaten Regency on HDI Klaten 2017. The campaign materials created by Difabel Klaten become its own inovation on HDI 2017. Visual Campaign by Difabel Klaten provides an interesting picture that reflecting itself as one of advocation's brand. Difabel Klaten producing a structured visual campaign on HDI 2017, there are Logo, Mascot, E-Banner, etc. This paper discusses about analysis of campaigns conducted by Difabel Klaten on HDI 2017. This paper using discritive analytics to analysis the campaign structure that can be discussed comprehensively. The result of this paper are: (1) there are consistency of visual communication ideas produced by Difabel Klaten; (2) the longlive creative ideas with advocacy spirit of Difabel that can be seen from Logo, Mascot, and other visual produced by Difabel Klaten.
\end{abstract}

Keyword: International Day of Persons with Disabilities, Campaign, Difabel Klaten

\section{PENDAHULUAN}

Sebagai salah satu langkah untuk membantu meningkatkan wawasan terhadap masyarakat adalah melalui kampanye di HDI. Beberapa daerah di Indonesia, melalui organisasi difabel dipelbagai bidang memperingati dengan cara masing-masing. Misalkan secara nasional pada Hari Disabilitas Internasional (HDI) 2017 diadakan di Prambanan, Yogyakarta. Acara ini 
dihadiri oleh Presiden Joko Widodo, sebagai bentuk ajakan nasional untuk lebih mengenal difabel. Pada tingkat kota/kabupaten, mengadakan acara longmarch atau seminar yang diselenggarakan oleh kelompok difabel di kota/kabupaten tersebut guna menunjuk-kan eksistensinya. Difabel di Karanganyar melalui organisasi Self Help Group (SHG) Karanganyar mengadakan longmarch pada Car Free Day untuk memeriahkan HDI.

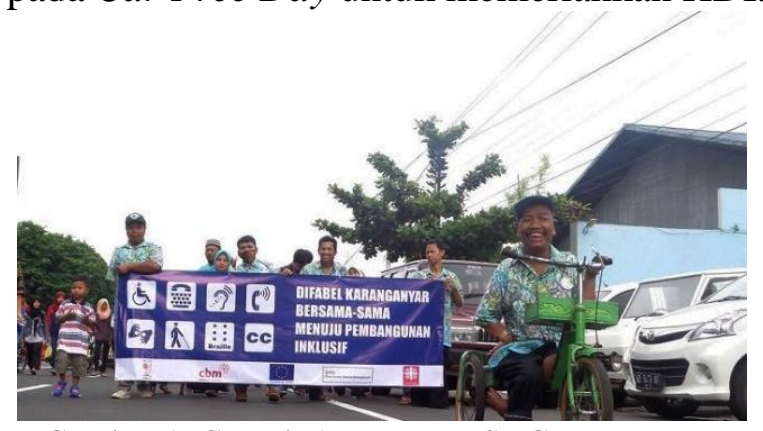

Gambar 1. Contoh Acara HDI: SHG Karangayar memperingati HDI 2016 (dok. Pribadi, 2016)

HDI juga dilakukan oleh Difabel Klaten dengan mengadakan rangkaian acara guna memperkenalkan apa itu difabel, dan bagaimana difabel itu ada ditengah-tengah masyarakat.

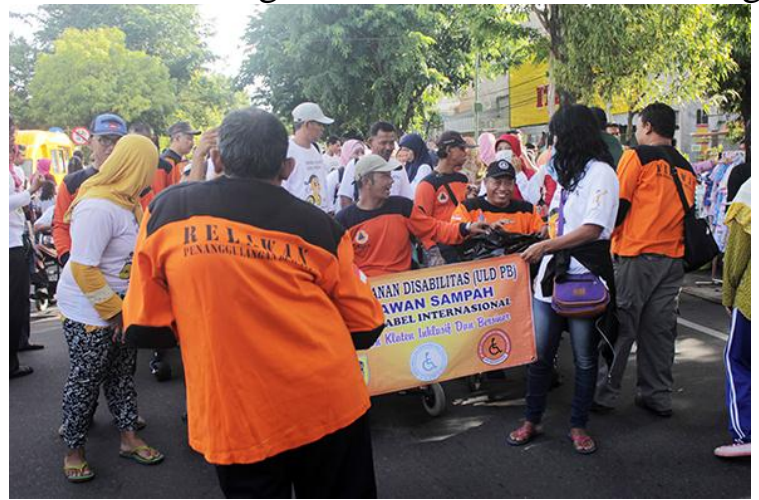

Gambar 2. Acara HDI Difabel Klaten mengenalkan kepada Masyarakat (dok. Pribadi, 2017)

HDI merupakan salah satu langkah untuk mendukung advokasi terhadap aksesibilitas difabel berbagai tingkat di Indonesia. Langkah-langkah advokasi secara aktif dilakukan oleh organisasi dan kelompok difabel di berbagai tingkat melalui kelompok dan perkumpulannya, dengan partisipasi aktif dalam berbagai kegiatan Pemerintah maupun non-Pemerintah, salah satunya HDI. Tujuan-nya adalah mendapatkan kesetaraan di segala bidang di masyarakat.

Perjuangan advokasi kelompok difabel juga memerlukan merek yang kuat, termasuk dalam HDI, agar menjadi kelompok yang memiliki posisi tawar dalam memperjuangkan hakhaknya sebagai warga negara; masyarakat tanpa diskriminasi, posisi yang sama di pemerintahan, dan berbagai aspek sosial. Sehingga kebijakan-kebijakan dalam strukural masyarakat tentang difabel terpenuhi. Melindungi, mengayomi, dan memberikan akses sesuai dengan ke-butuhan dari masing-masing difabilitas-nya. Pada Desember 2017, Difabel Klaten telah membuat materi-materi kampanye yang memuat ide-ide kreatif secara visual agar masyarakat tertarik untuk melihat mereka secara penuh. Bukan sebagai difabel saja, namun juga sebagai anggota masyarkat. Listya dan Angga (2018:64) mengatakan bahwa alam merancang identitas visual organisasi non-profit dilakukan sama halnya dalam membuat identitas organisasi profit, selain karena kebutuhan komunikasi visual, hal ini dilakukan agar konsep inklusi itu masuk dalam pembuatan logo yang tidak diskriminatif. Komunikasi visual sebagai sebuah proses sosial dimana orang mengubah pesan yang didalamnya termasuk visual-visual, bisa berupa gambar, lukisan, foto, video, film, dll (Kenney, 2009:20). 
Tulisan ini merupakan ringkasan dari analisis terhadap produksi visual pada Kampanye Sosial oleh Difabel Klaten yang menarik dalam mencermin-kan dirinya sebagai salah satu merek dalam perjuangan advokasi dari yang pernah ada. Difabel Klaten memproduksi kampanye secara visual secara terstruktur, dari Logo, Maskot, E-Banner, dll. Dibahas sesuai dengan pendekatan Desain Komunikasi Visual.

\section{METODE PENELITIAN}

Penelitian ini merupakan penelitian kualitatif dengan menggunakan pen-dekatan studi kasus karena tujuan penelitian ini adalah untuk memahami materi kampanye sebagai identitas organisasi difabel di Kabupaten Klaten dengan penguraian secara kualitatif dengan cakupan studi Kabupaten Klaten, dan lebih spesifik kelompok Difabel Klaten sebagai kasus khusus dalam penelitian ini, yang telah menggunakan merek Difabel Klaten sebagai entitas untuk memperkenalkan Difabel pada Hari Disabilitas Internasional (HDI) 2017 Kabupaten Klaten. Penelitian yang dilakukan, melibatkan beberapa data yang akan dikumpulkan. Foto, video, wawancara, observasi lapangan, yang berkaitan dengan Kampanye Sosial yang telah dilakukan oleh Difabel Klaten.

Penelitian yang dilakukan, melibat-kan beberapa data yang akan dikumpul-kan. Foto, video, wawancara, observasi lapangan, yang berkaitan dengan Kampanye Sosial yang telah dilakukan oleh Difabel Klaten guna mendapatkan data untuk dilihat dalam pandangan Desain Komunikasi Visual. Secara sederhana, akan dibentuk skema seperti di bawah ini:

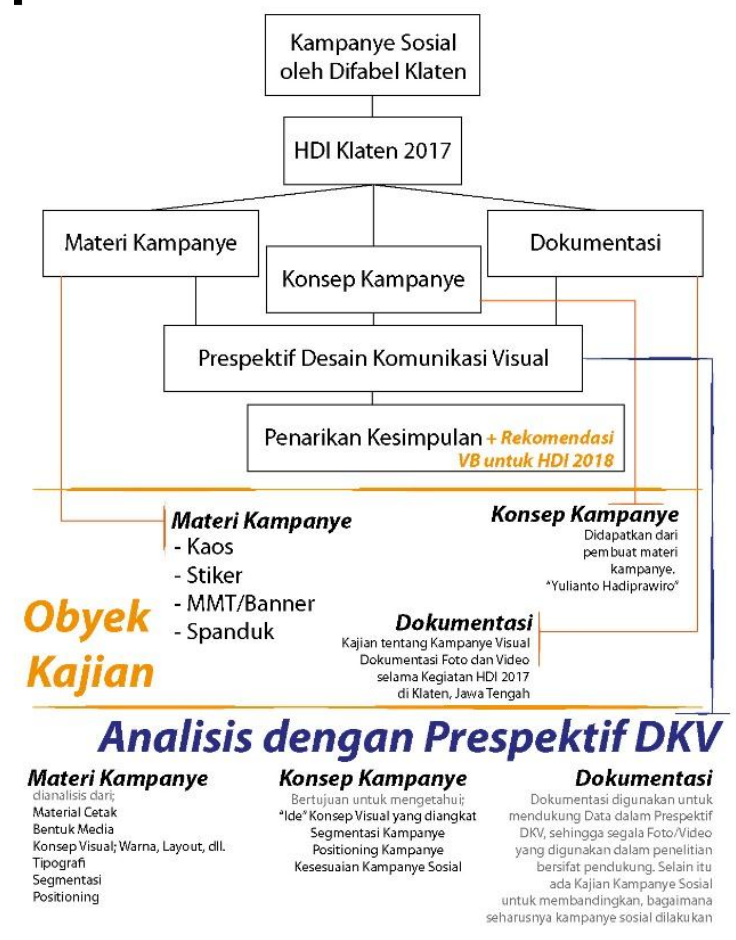

Gambar 3. Konstruksi Penelitian (dok. Pribadi, 2017)

\section{Materi Kampanye}

Kampanye adalah kegiatan komunikasi yang dikalukan secara terlembaga, penyelenggara kampanye bukanlah individu melainkan lembaga atau organisasi, dimana lembaga tersebut dapat berasal dari lingkungan pemerintah, maupun kalangan swasta atau lembaga swadaya 
masyarakat (Amalia Untarni dan Rahman, 2016:137). Kampanye sosial yang dilakukan oleh Difabel Klaten adalah kampanye yang terlembaga dan mengusung tema-tema difabilitas untuk diangkat dalam periklanan-nya.

Periklanan merupakan penyebaran informasi ataupun ide yang berkaitan tentang suatu gagasan, barang atau jasa, untuk 'membujuk' serta menarik orang agar berfikir, bersikap atau bertindak sesuai dengan keinginan pengiklan. Periklanan dianggap menciptakana ilusi. Iklan dapat menghardirkan kesan bahagia, lebih muda, dan sebagainya. Periklanan juga mencerminkan budaya. Sebuah strategi periklanan yang memuat penggunaan media-media periklanan melalui berbagai media komunikasi yang terorganisir, berkesinambungan dalam jangka waktu tertentu (timeframe) untuk memperkenalkan produk/jasa kepada masyarakat atau target audience, sering disebut sebagai kampanye iklan.Difabel Klaten merupakan "merek" yang digunakan untuk melakukan kampanye visual dalam Hari Disabilitas Internasional (HDI) 2017 Kabupaten Klaten. Difabel Klaten merupakan koalisi dari beberapa organisasi difabel di kabupaten Klaten, yang memiliki tujuan khusus sebagai nama dalam Hari Disabilitas Internasional (HDI) 2017 Kabupaten Klaten. Organisasi-organisasi yang masuk dalam Difabel Klaten diantaranya: Forum Komunikasi Masyarakat Peduli Difabel (FKMPD), Perkumpulan Penyandang Disabilitas Klaten (PPDK), Persatuan Tuna Netra Indonesia (PERTUNI), Gerakan Kesejahteraan Tuna Rungu dan Wicara Indonesia (GERKATIN), Paralympic Athlet Kabupaten Klaten, dan organisasi difabel lain yang ada di wilayah Kabupaten Klaten.

Pada September 2017, Difabel Klaten disepakati sebagai nama untuk merek dalam Kampanye HDI 2017 Kabupaten Klaten. Pada pertemuan tersebut dibuat juga materi-materi perancangan kampanye, agar merek untuk advokasi kelompok difabel di Klaten tetap terjaga sesuai dengan isu yang dibawa dalam Hari Disabilitas Internasional (HDI) yaitu kesetaraan.

Kampanye yang dilakukan oleh Difabel Klaten berupa kampanye sosial yang bertujuan besar untuk kesetaraan difabel. Dalam kampanye ini, juga dibantu dari Tim Abdimas Universitas Indraprasta PGRI untuk membentuk merek pada HDI 2017 Kabupaten Klaten. Tahapan perancangan, yang dilakukan menurut Hadiprawiro (2018:137-143) ada beberapa tahap:

1. Mereview kegiatan HDI, tahun sebelumnya

2. Memahami Brief

3. Brainstroming Ide

4. Membuat Moodboard

5. Membuat Konsep Perancangan

6. Membuat Sketsa

7. Mengerjakan desain computerized

8. Merancang Alternatif

9. Revisi Desain Final

Dari 9 tahap pembuatan materi kampanye untuk HDI 2017 Kabupaten Klaten, dapat dikelompokkan sebagai berikut:

Logo dan Maskot
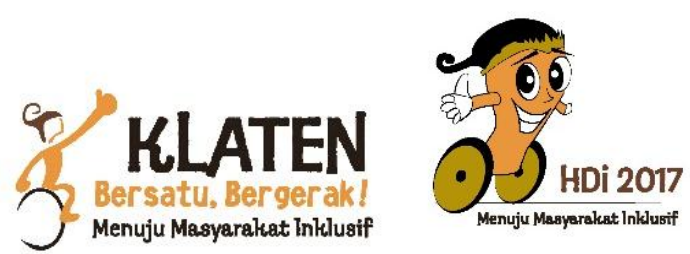

Gambar 4. Logo dan Maskot (Hadiprawiro, 2018)

Logo dan Maskot yang diciptakan memberikan kesan yang satu, meskipun tidak sama. Dawami (2017:137) me-nyatakan bahwa logo yang me-representasikan pergerakannya, dapat 
menjadi dasar ide logo yang dapat digunakan dalam perjuangan advokasi difabel. Dipertegas dengan visual-visual yang senada antara Maskot dan Logo. Dalam wawancara dengan Hadiprawiro (2018), mengatakan bahwa pada awalnya belum fokus membuat maskot, dalam keberjalanannya malah justru lebih seru dengan adanya maskot. Pendekatan menggunakan maskot bisa dicoba saat brainstroming, pada akhirnya ada maskot. Akhirnya muncul Maskot, Slogan/Tagline yang pada desain akhir yang digunakan oleh Difabel Klaten menjadi event lokalnya klaten, gerakan Difabel Klaten.

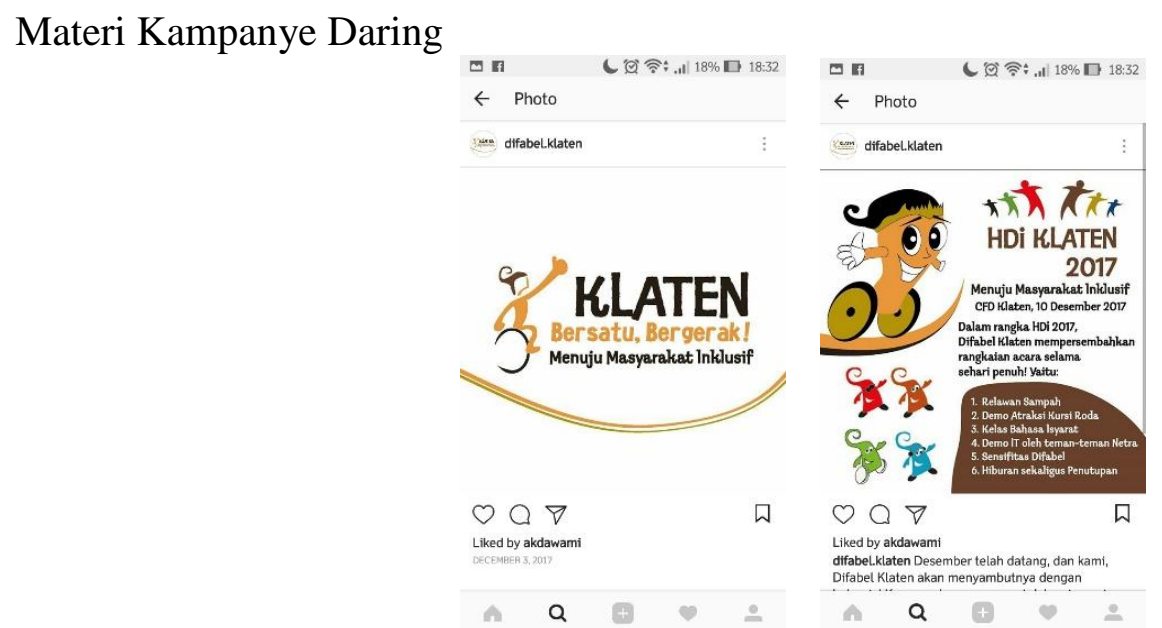

Gambar 5. e-banner informasi pada Instagram (Instagram Difabel Klaten, 2017)

Pembentukan Logo dan Maskot ter-lihat juga beragam pada @difabel.klaten, tidak monoton dari setiap materi kampanye yang telah dibuat sesuai dengan konsep kampanye yang telah digunakan oleh Difabel Klaten. Desain-desain yang diciptakan tidak monoton pada satu tipe desain, namun ada beberapa desain seperti pada media daring diatas. Maka dapat disimpulkan, keberagaman dari kampanye HDI ini juga tercipta dan sesuai dengan keinginan dari Difabel Klaten untuk setara. Ritme yang digunakan juga terlihat sama dengan visual garis lengkung yang sama antara satu posting media daring satu dengan posting media daring yang lain.

Materi Kampanye Offline

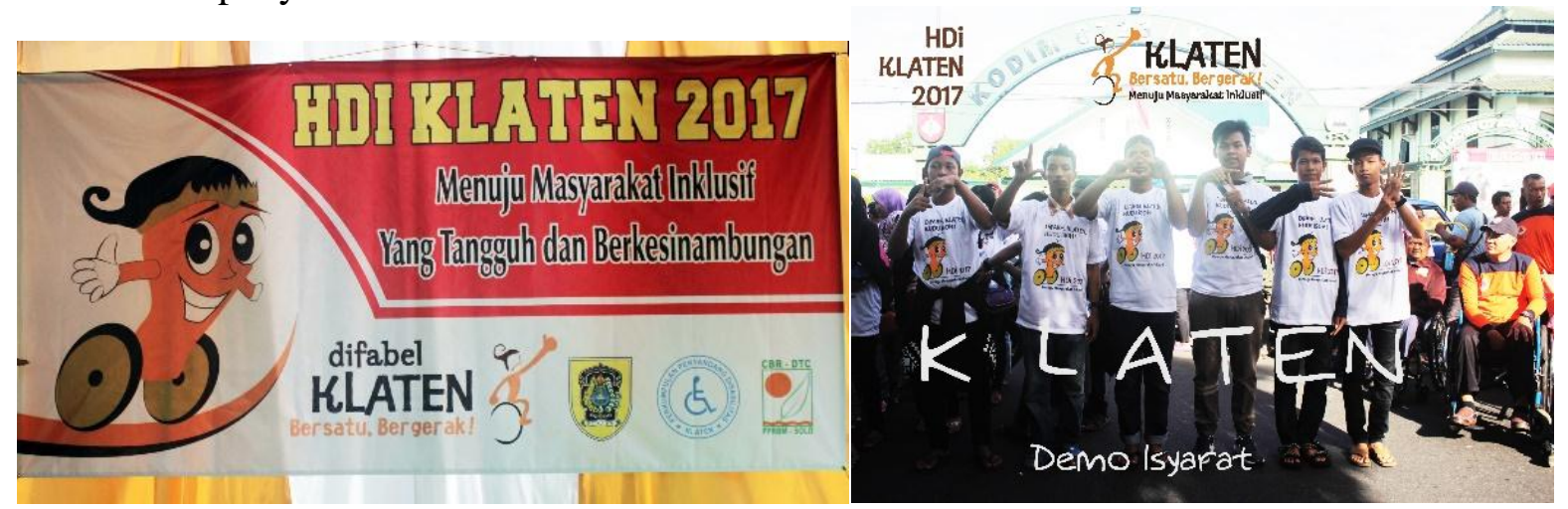

Gambar 6. Kaos dan banner acara pada HDI (Pribadi, 2017)

Pada Kampanye Sosial HDI 2017 Kabupaten Klaten ini tidak hanya menggunakan materi kampanye dengan tema Difabel Klaten yang diunggah di daring (online), tapi juga diterapkan di media kampanye konvensional; banner dan kaos. Selain karena memang peserta dari HDI 
adalah Difabel di seluruh Klaten, kolaborasi antar organisasi sosial juga tidak bisa dipisahkan. Sehingga, materi-materi kampanye yang muncul juga beragam.

\section{Analisis}

Sihombing (2003: 2) dalam buku Desain Grafis, menyatakan bahwa salah satu aktivitas yang sangat penting dalam kehidupan manusia adalah ber-komunikasi, baik itu dalam melakukan kegiatan belajar, bekerja maupun ber-main. Secara tidak sadar dalam kesehari-an manusia berpartisipasi dalam komunikasi, baik sebagai si pengirim pesan maupun sebagai penerima pesan. Secara visual, komunikasi yang dilaku-kan manusia juga terus-menerus dilaku-kan, dari mulai bangun pagi sampai hari berikutnya. Asosiasi terhadap komunikasi visual inilah yang mencipta-kan persepsi-persepsi yang berkaitan antara satu objek dengan objek yang lain dalam kehidupan manusia. Sehingga produksi visual dari pikiran manusia akan mempengaruhi keterhubungan dalam rangsangan persepsi manusia, atau dalam psikologi disebut sebagai Gestalt. Menurut (Koffka, dkk, 1923:25) Gestalt adalah merupakan teori dari bidang ilmu psikologi yang menjelaskan tentang proses persepsi melalui pengorganisasian komponen-komponen sensasi dalam pengindraan yang memiliki hubungan, pola, ataupun kemiripan menjadi kesatuan.

Konsistensi grafis yang muncul dalam HDI 2017 Kabupaten Klaten memiliki kesamaan, menurut Listya dan Angga (2018:56) dalam menciptakan konsistensi visual diperlukan kesatuan antar elemen-elemen identitas visual, termasuk gaya grafis. Hadiprawiro (2018) mengatakan bahwa

Awalnya rencana perancangan ini akan mengacu pada logo. Namun ternyata pihak Klaten meminta untuk membuat kaos, agar masuk produksi terlebih dahulu. Maka acuannya berubah, dari logo, menjadi kaos yang ada maskot dan logonya.

Kesatuan yang terjadi pada kampanye tersebut terkoneksi dengan adanya maskot dan logo, serta pewarnaan yang cerah, dengan menggunakan warna orange dan coklat. Pada kampanye ini acuan untuk membentuk materi kampanye adalah kaos, maka desain acuan kaos dapat menjadi poin utama dalam pembahasan kajian visual ini.

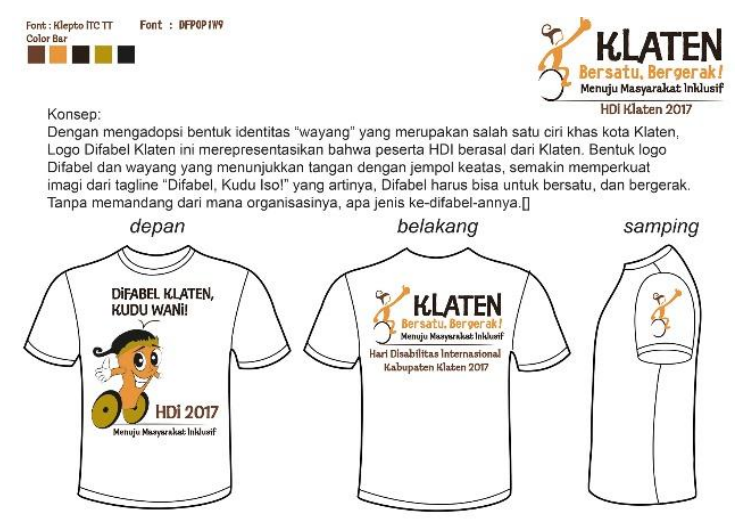

Gambar 7. Desain Kaos HDI Klaten (Pribadi, 2017)

Prinsip dasar desain ialah pengorganisasian unsur-unsur dalam dasar desain dengan memperhatikan prinsip-prinsip menciptakan desain serta mengaplikasikan kreativitasnya (Jefkins, 1997: 245). Melihat prinsip desain dalam Desain Komunikasi Visual, desain yang digunakan dalam Kampanye HDI 2017 memiliki konsistensi yang cukup tinggi, terlihat dari Logo dan Maskot yang diciptakan memberikan kesan yang satu, meskipun tidak sama. Dipertegas dengan visual-visual yang senada antara Maskot dan Logo. Dalam wawancara dengan Hadiprawiro (2018), mengatakan bahwa pada awalnya belum fokus membuat maskot, 
dalam keberjalanannya malah justru lebih seru dengan adanya maskot. Pendekatan menggunakan maskot bisa dicoba saat brainstroming, pada akhirnya ada maskot. Akhirnya muncul ada Maskot, Slogan/Tagline yang akhirnya menjadi event lokalnya klaten, gerakan Difabel Klaten.

Tema warna yang digunakan juga memberikan gambaran, bahwa kesatuan ingin diciptakan dengan menggunakan warna kalem. Yulianto Hadiprawiro, sebagai desainer dalam wawancara 13 April 2018 mengungkapkan bahwa;

"Lebih baik konsisten. Sangat mungkin kalau dibuat tahun berikutnya, akan lebih baik tidak berubah total. Pada desain pertama, dirasa belum begitu sempurna, masih bisa diolah dimodif, jangan total diganti. Mirip dengan perubahannya logo starbucks. Ketika hanya basisnya yang bermain warna hijau dan putih. Dengan icon, mungkin di 2018, setelah kampanye 2017, lebih dirapikan dengan font atau treatment warna yang sama. Jadi, perubahannya tidak begitu drastis. Agar masyarakat, akan merespon di tahun yang berbeda, pada tahun berikutnya ternyata HDI mengadakan kembali. Mereka akan menyimpan memori mereka tahun lalu, ketika tahun ini muncul lagi, akan paham, berarti ini penyelenggaranya sama."

Kesatuan yang dibangun dari Logo dan Maskot membentuk media-media aplikasi lain yang sesuai dengan konsep kesetaraan dari Hari Disabilitas Internasional (HDI) 2017 Kabupaten Klaten. Konsep yang digunakan juga menggunakan jempol, yang secara universal, menggambarkan kebaikan. Seperti orang yang bermaksud untuk memberi tanda "baik" kepada orang lain, maka dia akan mengacungkan jempol-nya. Keseimbangan yang digunakan adalah keseimbangan asimetris, yang berarti tidak menggunakan elemen visual yang sama antara kiri dan kanan dalam Logo dan Maskot, namun menggunakan rasa visual, yang seakan-akan seimbang.

Irama yang diciptakanpun juga tidak keluar dari pewarnaan dan elemen desain yang telah dibuat. Bisa dilihat bagaimana logo dan maskot terus menerus digunakan dalam Banner dan EBanner. Konsistensi yang terus-menerus ada, memberikan penekanan bahwa memang kampanye ini merupakan kampanye yang dapat memberikan dampak kepada masyarakat secara umum, bahwa difabel itu memang seharusnya setara, sesuai dengan perjuangan mereka. Secara singkat dapat diinterpretasikan materi kampanye kaos dalam Hari Disabilitas Internasional (HDI) 2017 Kabupaten Klaten, sebagai berikut:

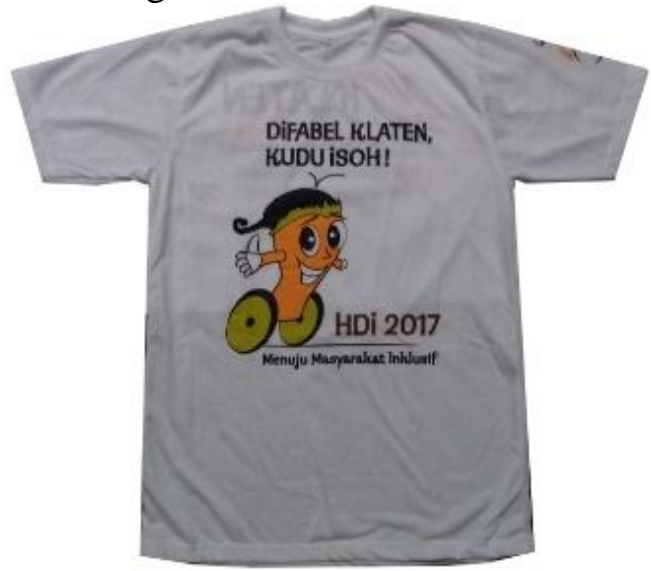

Gambar 8. Kaos Cetak HDI tampak Depan (Pribadi, 2017)

Analisis Visual Kaos Tampak Depan

Material: Combat Cotton 30s

Teknik Cetak: Cetak Sablon 
Konsep Visual: Pada bagian depan kaos terdapat ikon maskot dari HDI 2017, dan tulisan "Difabel Klaten, Kudu Isoh!" dengan tagline Menuju Masyarakat Inklusif. Untuk tulisan menggunakan warna hitam dan coklat agar terlihat jelas. Dengan adanya copywriting (tulisan) dengan menggunakan bahasa lokal, maka dapat membantu masyarakat mengenali, bahwa Difabel memang harus bisa layaknya masyarakat pada umumnya.

Tipografi: menggunakan jenis huruf san serif, karena tingkat readibility nya cukup tinggi.

Segmentasi: Laki-laki dan Perempuan semua kalangan.

Positioning: Masyarakat Inklusi.

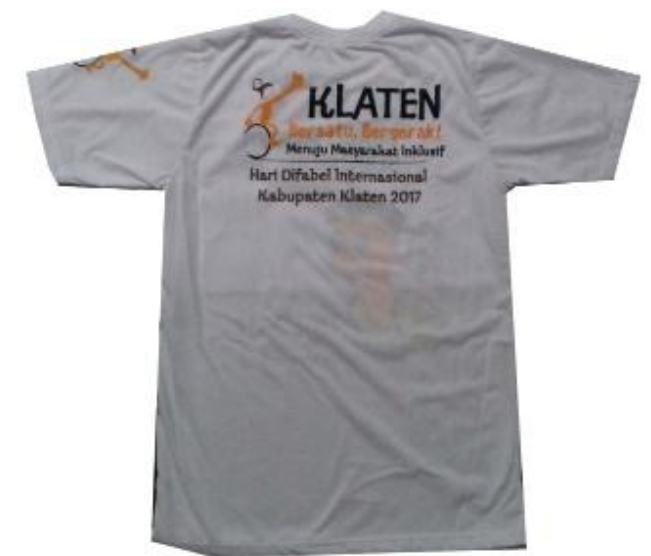

Gambar 9. Kaos Cetak HDI tampak Belakang

(Pribadi, 2017)

Analisis Visual Kaos Sisi Belakang

Material: Combat Cotton 30s

Teknik Cetak: Cetak Sablon

Konsep Visual: Bagian ini terdapat ikon Difabel sebagai logo, dan tulisan KLATEN dengan tagline "Bersatu, Bergerak! Menuju Masyarakat Inklusif Hari Difabel Internasional Kabupaten Klaten 2017'. Menggambarkan semangat difabel klaten yang terus menerus ada dengan warna yang mendukung dari warna ikon maskot HDI 2017.

Tipografi: menggunakan jenis huruf san serif, karena tingkat readibility nya cukup tinggi.

Segmentasi: Laki-laki dan Perempuan semua kalangan.

Positioning: Masyarakat Inklusi

Melihat hasil analisis di atas, dapat dikatakan bahwa dalam HDI 2017 Kabupaten Klaten memang mencermin-kan masyarakat inklusi dengan melihat maskot dan logo yang memiliki ciri khusus kursi roda. Kesinambungan antara ide kreatif dan materi kampanye telah terhubung dengan baik. Hal ini diakui oleh Hadiprawiro (2018) sebagai pem-buat materi kampanye agar interpretasi masyarakat sama, antara apa yang di-kampanyekan, dan siapa yang melakukan kampanye sosial ini. Dengan pesan visual yang sama, maka akan membuat konsistensi Difabel Klaten diterima di masyarakat secara umum.

Konstruksi visual yang mengguna-kan lokalitas tentu akan lebih diterima dengan baik, sesuai dengan daerah yang menjadi target audience (target pen-dengar dan pelihatnya) dari Kampanye ini. Copywriting yang sesuai dengan daerah harus dicari dengan baik, dan teliti selama melakukan eksplorasi ide, dan hal ini dapat dilihat bagaimana kebutuhan visual untuk kampanye pada HDI 2017, cukup memberikan gambaran bahwa wilayah yang ditarget dari kampanye ini adalah wilayah yang memiliki budaya Jawa. 


\section{SIMPULAN}

Hari Disabilitas Internasional (HDI) merupakan waktu yang tepat untuk dapat menyuarakan tema kesetaraan, agar komunikasi visual dapat dijalankan dengan baik oleh Difabel Klaten. Kajian prespektif Desain Komunikasi Visaul dari pembahasan sebelumnya dapat di-simpulkan bahwa konsistensi, kesatuan, penekanan, keseimbangan, penekanan dalam hal visual, bisa dibilang sesuai dengan konsep Desain Komunikasi Visual. Difabel Klaten dapat meng-evaluasi yang bisa digunakan di tahun berikutnya.

Hasil yang muncul dari analisis secara Desain Komunikasi Visual adalah: (1) terdapat konsistensi atas ide-ide komunikasi visual yang diproduksi oleh Difabel Klaten; (2) adanya kesinambung-an antar ide kreatif dengan semangat perjuangan Difabel yang dilihat dari logo, maskot, dan produksi visual lainnya. Difabel Klaten sebenarnya dapat me-maksimalkan kolaborasi dengan me-maksimalkan potensi-potensi visual yang mendukung kebutuhan dalam Hari Disabilitas Internasional (HDI) ditahun berikutnya.

\section{DAFTAR PUSTAKA}

Dawami, A. (2017). Logo sebagai Komunikasi Visual dari Identitas Organisasi Difabel Tuli. Magenta | Official Journal STMK Trisakti, 1(02), 133-141. Retrieved from http://www.magenta.mediakomtrisakti.ac.id/magenta/index.php/magenta/article/view/ 14

Hadiprawiro, Y. (2018). Desain Logo dan Maskot "Difabel Klaten" sebagai Brand Awarness Kampanye Sosial Peduli Masyarakat Disabilitas di Klaten, Jawa Tengah. Jurnal Desain 5 (02), 135-144, Januari 2018

Jefkins, F. (1997). Periklanan, Cetakan Pertama, Edisi Ketiga, Jakarta; PT. Erlangga.

Kenney, K. (2009). Visual Communication Research Design. New York: Routledge

Koffka, K.., Wertheimer, M., Köhler, W. (1923). Investigation Gestalt Theory. New Jersey: John Wiley

Listya, A. \& Dawami, A. K.. (2018). Perancangan Logo Organisasi Forum Komunikasi Masyarakat Peduli Difabel (FKMPD) Klaten. Jurnal Desain 5 (02), 61-73, Januari 2018.

Sihombing, D. (2001). Tipografi dalam Desain Grafis. Yogyakarta: Penerbit Andi.

Untarni, F. A., \& Rahman, Y. (2016). Perancangan Kampanye Sosial Meningkatkan Minat Baca Anak Melalui Bapusipda di Kota Bandung. Desain Komunikasi Visual, Manajemen Desain Dan Periklanan (Demandia), 134145.doi:10.25124/demandia.v1i02.27

\section{Wawancara}

Yulianto Hadiprawiro, 40 tahun, (2018), Kreator Logo dan Maskot HDI Klaten 